\title{
Foregut motor function in chronic renal failure
}

\author{
A M Ravelli, S E Ledermann, W M Bisset, R S Trompeter, T M Barratt, P J Milla
}

\begin{abstract}
In children with chronic renal failure (CRF) anorexia, nausea, and vomiting are common yet poorly understood symptoms. We studied oesophageal and gastric motor function in 12 children (age 7 months -6.8 years) with severe CRF not undergoing dialysis who had persistent anorexia and vomiting. Eight of 12 patients had significant gastro-oesophageal reflux (reflux index $5 \cdot 2 \%$ to $21.9 \%$, mean $11.3 \%$; controls $<5 \%$ ), $7 / 10$ had altered gastric half emptying times ( $\left.T^{1 / 2}\right)$ for $5 \%$ glucose or milk (glucose meal-controls: 8-14 min, two CRF patients: 18-25 min; milk meal-controls: 48-72 min, five CRF patients $27,28,82,83$, and $110 \mathrm{~min}$ ). Gastric antral electrical control activity was abnormal in 6/11 patients, with different types of gastric dysrhythmias whereas the remainder and controls showed a regular dominant frequency of $0.05 \mathrm{~Hz}$. In $7 / 9$ patients fasting serum gastrin concentration was raised (53 to $>400$, mean $168 \mathrm{pmol} / \mathrm{l}$, controls $<40$ pmol/1). All CRF patients with anorexia and vomiting had one or more disorder of foregut motility. The nature and variety of the motor disorders and the raised concentrations of circulating gastrin suggest that the normal environment generated by CRF affects the function of the smooth muscle of the foregut.
\end{abstract}

(Arch Dis Child 1992;67:1343-7)

Children with chronic renal failure (CRF) commonly suffer from anorexia, nausea, vomiting, and failure to thrive. ${ }^{1}$ Our current understanding of the cause of these symptoms is limited and treatment is largely empirical and ineffective. It is generally accepted that vomiting may occur as a result of gastro-oesophageal reflux (GOR) or by initiation of the emetic reflex. The latter is associated with prodromal symptoms such as nausea, gastric and oesophageal dysmotility and reflex contractions of the intercostal, diaphragmatic, and anterior abdominal muscles. ${ }^{2}$ Regurgitation however is effortless and not associated with any prodromal symptoms. $^{3}$ Whether one or both of these mechanisms is responsible for vomiting in children with CRF has not been previously studied.

In this study we have assessed foregut motor function and its regulation in children with CRF who were failing to thrive and had symptoms of anorexia and vomiting.

\section{Patients and methods}

PATIENTS

Twelve children (10 boys and two girls, mean age $2 \cdot 17$ years, range 7 months $-6 \cdot 8$ years) with $\mathrm{CRF}$ (mean estimated glomerular filtration rate 11 (range $6-25) \mathrm{ml} / \mathrm{min} / 1 \cdot 73 \mathrm{~m}^{2}$ ) receiving conservative medical management but not requiring dialysis were studied. The primary cause of renal disease was renal dysplasia $(n=7)$ or obstructive uropathy $(n=5)$. At the time of study the mean height SD score was $-2 \cdot 6(-4 \cdot 0$ to $-1 \cdot 7)$ and mean weight SD score was $-2 \cdot 5$ $(-3.8$ to $-1 \cdot 3)$. All children were anorexic and/ or had a history of vomiting at the time of study. Eleven of the 12 required nasogastric tube feeding in order to achieve an adequate energy intake.

\section{CONTROLS}

Overall 50 subjects (age 3 months-17 years) acted as controls: 22 for GOR, 12 for gastric emptying, and 16 for gastric electrical activity. Twelve were normal healthy children and the others had eating disorders $(n=23)$, recurrent respiratory infections $(n=6)$, cyclical vomiting $(n=5)$, postenteritis enteropathy $(n=2)$, Crohn's disease in relapse $(n=2)$; none had irritable bowel syndrome or were referred for a suspected gastrointestinal motility disorder. After detailed motility investigation including intraoesophageal $\mathrm{pH}$ monitoring, antroduodenal manometry and electrogastrography, no evidence of such a disorder could be found.

\section{METHODS}

All patients with a history of vomiting had a barium meal and follow through examination. Foregut motor function was assessed by measuring intraoesophageal $\mathrm{pH}$, gastric emptying, and gastric antral electrical activity. Regulation of gastrointestinal motility was assessed by measuring polypeptide hormones. The study was approved by the ethical committee of the Hospital for Sick Children, Great Ormond Street.

\section{GOR}

A well validated ambulatory intraoesophageal pH monitoring system (Synectics Medical) utilising an antimony electrode was used over a six hour postprandial period, which has been shown to be comparable with a 24 hour recording for the detection of GOR in children with vomiting and feeding problems. ${ }^{4}$ Two parameters were considered: (1) percentage of time spent with an intraoesophageal $\mathrm{pH}$ below 4 (reflux index or RI) and (2) duration of the longest reflux episode. GOR was graded as 
normal (RI $\leqslant 5 \%$ ), mild (RI 5\%-10\%), moderate (RI 10\%-20\%), and severe (RI > 20\%).

\section{Gastric emptying}

Gastric emptying was measured by applied potential tomography. ${ }^{5}$ Either $20 \mathrm{ml} / \mathrm{kg}$ of cows' milk $(+0.22 \mathrm{~g}$ sodium chloride $/ 100 \mathrm{ml}$ to increase electrical conductivity) or $5 \%$ glucose were given as test meal. At the end of the study an emptying curve was computed, maximum postprandial resistivity noted, and time to half emptying $\left(T^{1 / 2}\right)$ calculated. Six patients were tested after a milk meal, three after a glucose meal, and three with both meals on two different occasions.

\section{Gastric antral electrical control activity}

Electrical control activity was recorded by surface electrogastrography ${ }^{6}$ over a one hour period after an overnight fast. A standardised meal (milk 10-20 ml/kg) was given after 30 minutes to initiate postprandial activity. Electrical activity was recorded from four pairs of silver/silver chloride bipolar skin electrodes (impedance $2 \cdot 5+2 \cdot 0 \mathrm{KOhms}$ ) placed over the abdomen halfway between the xiphisternum and the umbilicus. The signal was then amplified and low pass filtered at $0.33 \mathrm{~Hz}$ before being displayed on a Gould 8 channel polygraph and simultaneously digitalised at $1 \mathrm{~Hz}$ by an analogue to digital converter Data Translation DT 2801A mounted in an IBM AT compatible personal computer (Zenith 248). Running spectral analysis of the signal was performed using a sequence of computerised algorithms (PC-DATS, Prosig Computer Consultants) customised by the authors. Each one hour recording was divided into 55 partially overlapping segments of 128 seconds. Each segment was band pass filtered at 0.01 and $0.25 \mathrm{~Hz}$ and the frequency spectrum was derived by autoregressive modelling. The dominant frequency was calculated and the resulting analysis was displayed as a pseudo three dimensional plot.

\section{Polypeptide hormones}

Fasting blood samples were collected in $5 \mathrm{ml}$ lithium heparin test tubes with $0.2 \mathrm{ml}$ Trasylol. The samples were centrifuged, the serum removed, and they were immediately frozen in liquid nitrogen and then stored at $-70^{\circ} \mathrm{C}$. Serum concentrations of gastrin, glucagon, pancreatic polypeptide, vasoactive intestinal polypeptide, and neurotensin were measured using well validated radioimmunoassays (Professor S R Bloom, Supraregional Assay Service, Hammersmith Hospital, London).

\section{STATISTICAL ANALYSIS}

Given the small numbers of subjects tested and the variability of data distribution, arbitrary upper and lower limits of normal (greater than 2SD from the controls' mean) were established. Patients groups were compared with controls using the Mann-Whitney test.

\section{Results}

GOR

In 22 age matched controls mean (SD) RI was $2 \cdot 22(1 \cdot 22) \%$ compared with $8 \cdot 02(6 \cdot 79) \%$ in CRF patients (difference between medians $-5 \cdot 21,95 \%$ confidence interval $-7 \cdot 86$ to $-1.18 ; p=0.01$ ), and RIs are shown in fig 1 . Eight patients with CRF had GOR (RI $>5 \%)-$ five mild, two moderate and one severe-and in these mean RI was $11 \cdot 3$ (range $5 \cdot 2-21 \cdot 9$ ) $\%$. Three patients with GOR also had long reflux episodes (22, 27, and $30 \mathrm{~min})$ exceeding the upper limit of controls $(20 \mathrm{~min})$. The severity of reflux was not directly related to the degree of the CRF.

\section{Gastric emptying}

Only two patients managed to drink the full test meal; in the remainder $(n=10)$ it was given by nasogastric tube but six could only tolerate volumes of 10 to $15 \mathrm{ml} / \mathrm{kg}$, that is $50 \%$ to $75 \%$ of the meal volume normally used. Four patients (three tube fed) vomited during the test. As expected, the $\mathrm{T}^{1} 1 / 2$ was considerably slower with milk than with $5 \%$ glucose in both patients and controls (fig 2). After the milk meal, the mean (SD) $\mathrm{T}^{1} 1 / 2$ was $61.5(8.6) \mathrm{min}$ in six healthy controls (normal limits: 40 and $80 \mathrm{~min}$ ) and $62 \cdot 8$ $(26.8) \mathrm{min}$ in nine CRF patients. After the glucose meal, the mean (SD) $\mathrm{T}^{1} 1 / 2$ was $10 \cdot 7(2 \cdot 3)$ min in six other healthy controls (normal limits: 6 and $16 \mathrm{~min}$ ) and $13.2(7 \cdot 6) \mathrm{min}$ in six CRF patients. Seven patients had abnormal gastric emptying. Two had accelerated gastric emptying, one after the milk meal and another after both milk and glucose meals $\left(\mathrm{T}^{1} 1 / 228,27\right.$, and $5 \mathrm{~min}$ respectively). Five had delayed emptying, three after the milk meal $\left(T^{1} 1 / 282,83\right.$, and 110 $\mathrm{min})$ and two after the glucose meal ( $\mathrm{T} 1 / 218$ and $25 \mathrm{~min}$ ). Although as a group patients did not significantly differ from controls (milk meal: difference between medians $-1.25,95 \cdot 2 \%$ confidence interval -24.0 to $24.0, p=0.95$;

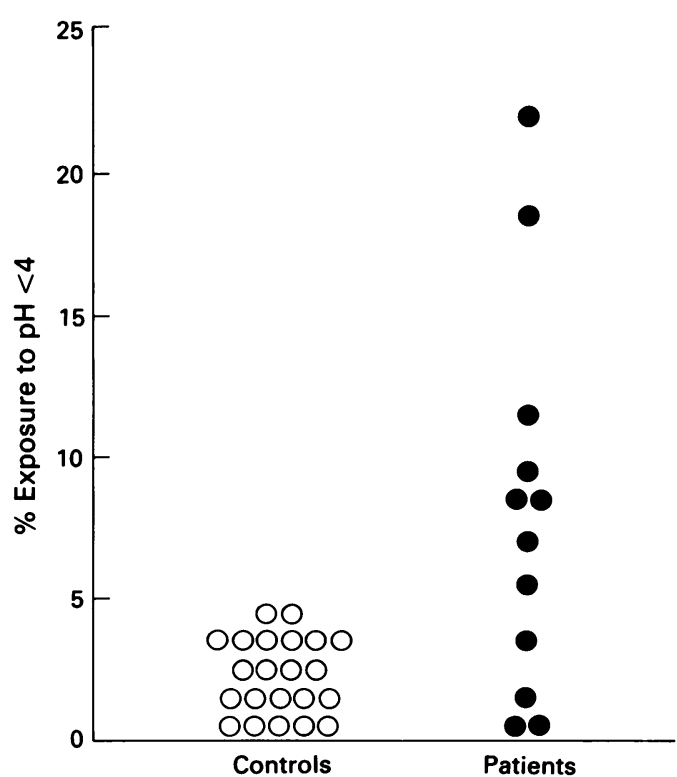

Figure 1 Percentage of exposure to intraoesophageal pH $<4(R I)$ in 22 controls and 12 patients with $C R F$ 
glucose meal: difference between medians $-1 \cdot 0,95 \cdot 2 \%$ confidence interval $-11 \cdot 0$ to $5 \cdot 0$; $p=0.87$ ), the variability of their $T^{1 / 2}$ was clearly higher than that of controls. Of those patients with abnormal gastric emptying, half were intolerant of the test meal. Among the patients with delayed emptying, two vomited during the
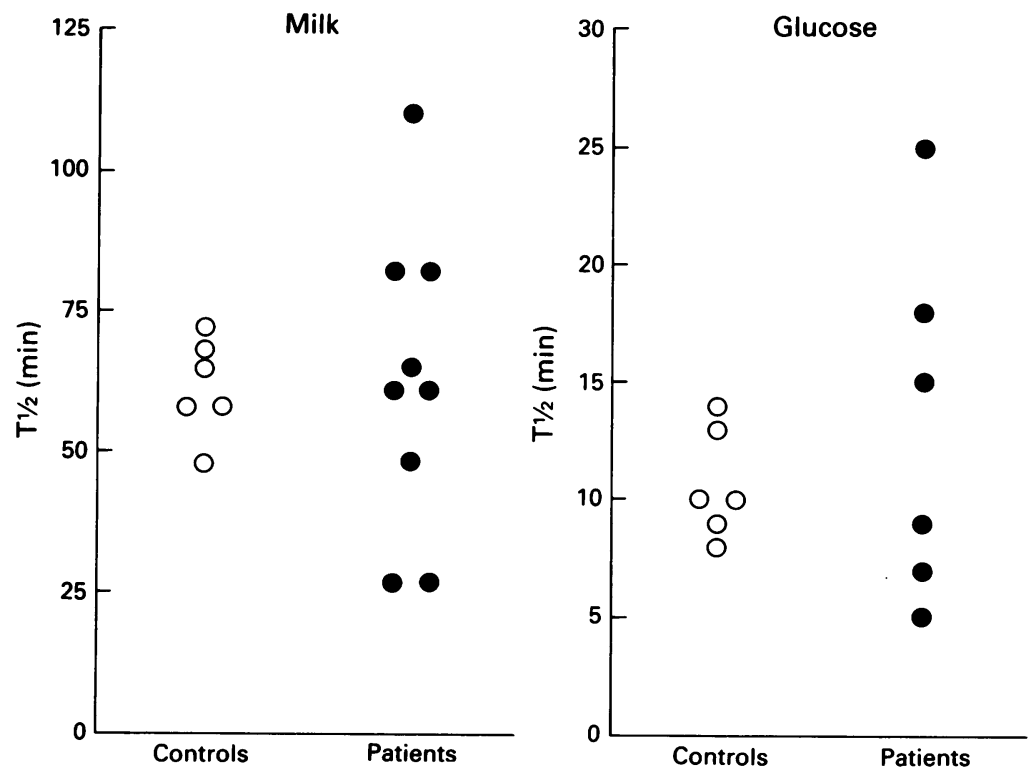

Figure 2 Gastric half emptying times (T1/2) after a milk meal and a $5 \%$ glucose meal in 12 healthy controls and 12 children with CRF. Note that the time scale on the $Y$ axis of the right hand scatterplot is expanded. test and one received a reduced meal volume. One patient with accelerated emptying vomited at the end of the test.

Gastric antral electrical control activity

Electrical control activity occurred at a mean frequency of $0.05(0.04-0.06) \mathrm{Hz}$ in 16 controls and in five patients. In 6/11 children with CRF a number of different dysrhythmias of antral electrical control activity were detected. One patient had a tachyarrhythmia $(0.15 \mathrm{~Hz})$, two had a bradyarrhythmia $(0.02$ and $0.03 \mathrm{~Hz}$ respectively), and three had an unstable electrical control activity (no dominant frequency detectable). All dysrhythmias occurred during the fasting as well as the postprandial period. These dysrhythmias are shown as pseudo three dimensional running spectral frequency plots in fig 3.

\section{Polypeptide hormones}

Fasting serum concentrations of vasoactive intestinal polypeptide, pancreatic polypeptide, glucagon, and neurotensin were within the reference range in all but two patients, one with vasoactive intestinal polypeptide values of 48 $\mathrm{pmol} / \mathrm{l}$ (reference range $<30$ ) and another with pancreatic polypeptide values of $393 \mathrm{pmol} / \mathrm{l}$ (reference range $<300$ ). Fasting serum gastrin was significantly raised in $7 / 9$ patients. These seven had a mean value of $168 \mathrm{pmol} / \mathrm{l}$ and a range

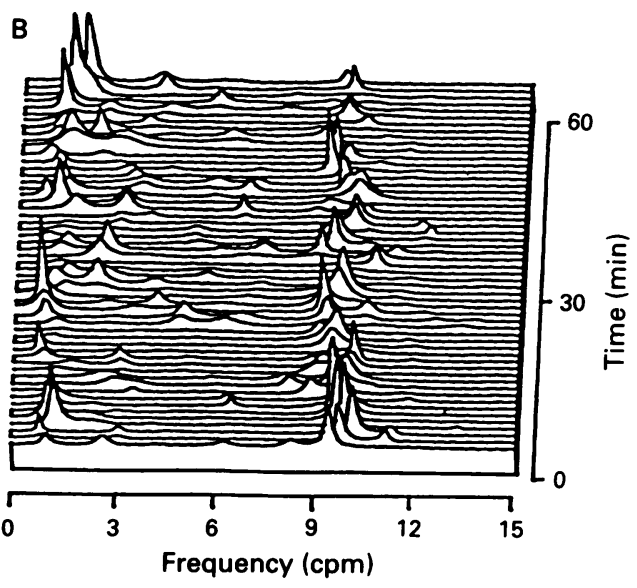

C
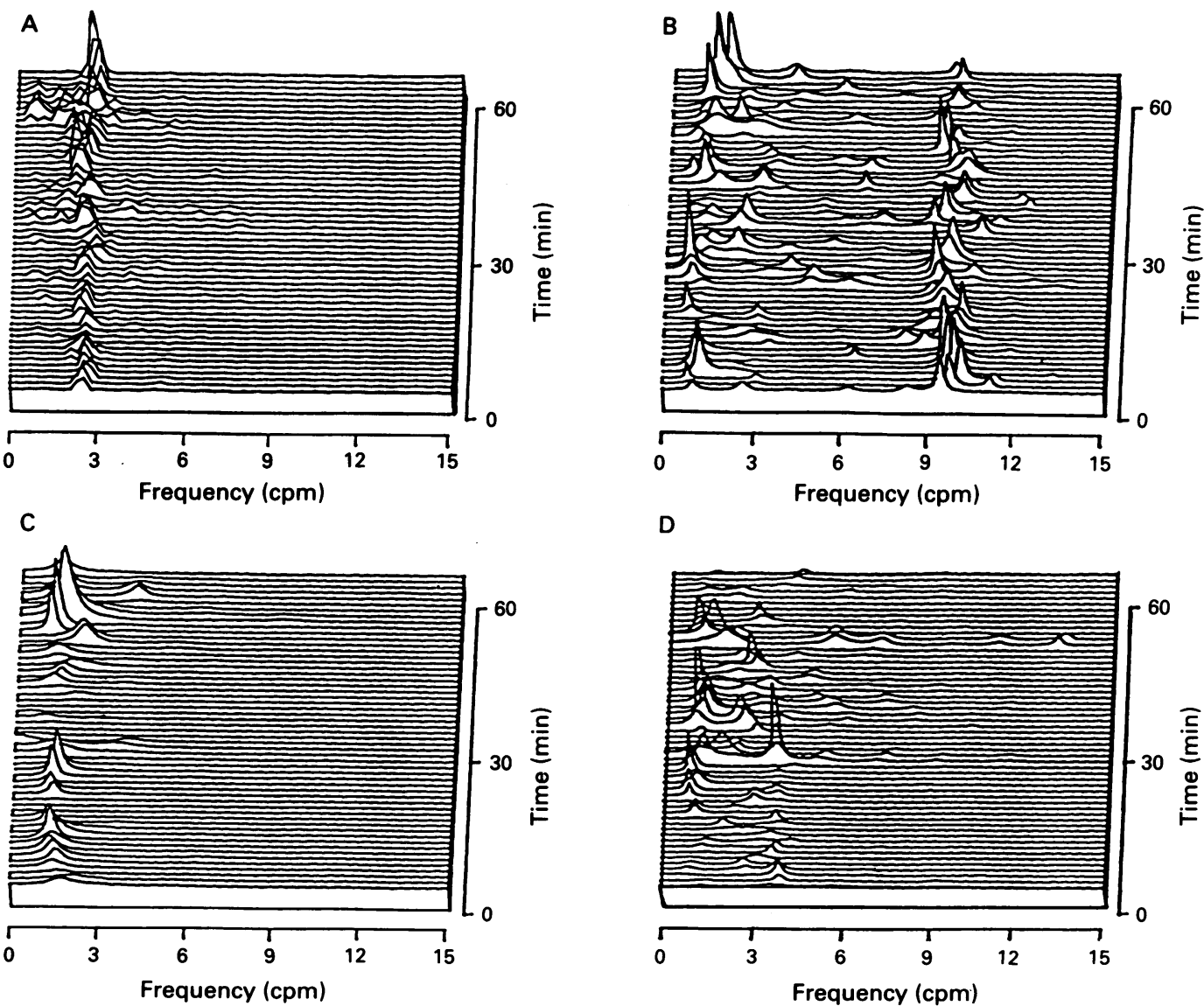

Figure 3 Pseudo three dimensional running spectral frequency plots of electrogastrography recorded in four children with chronic renal failure. Normal electrical control activity $(A)$, a tachyarrhythmia $(B)$, a bradyarrhythmia $(C)$, and unstable electrical control activity (D) are shown. Frequencies are expressed as cycles per minute (cpm), where $3 \mathrm{cpm}=0.05 \mathrm{~Hz}$. 
Results of foregut motility assessment

\begin{tabular}{|c|c|c|c|}
\hline $\begin{array}{l}\text { Patient } \\
\text { No }\end{array}$ & GOR & $\begin{array}{l}\text { Gastric } \\
\text { emptying }\end{array}$ & $\begin{array}{l}\text { Gastric antral } \\
\text { electrical control } \\
\text { activity }\end{array}$ \\
\hline $\begin{array}{r}1 \\
2 \\
3 \\
4 \\
5 \\
6 \\
7 \\
8 \\
9 \\
10 \\
11 \\
12\end{array}$ & $\begin{array}{l}\text { Moderate } \\
\text { Mild } \\
\text { Normal } \\
\text { Moderate } \\
\text { Severe } \\
\text { Mild } \\
\text { Mild } \\
\text { Normal } \\
\text { Normal } \\
\text { Mild } \\
\text { Mild } \\
\text { Normal }\end{array}$ & $\begin{array}{l}\text { Delayed } \\
\text { Delayed } \\
\text { Normal } \\
\text { Accelerated } \\
\text { Normal } \\
\text { Accelerated } \\
\text { Normal } \\
\text { Delayed } \\
\text { Normal } \\
\text { Delayed } \\
\text { Normal } \\
\text { Delayed }\end{array}$ & $\begin{array}{l}\text { Normal } \\
\text { Tachyarrhythmia } \\
\text { Unstable } \\
\text { Normal } \\
\text { Unstable } \\
\text { Bradyarrhythmia } \\
\text { Normal } \\
\text { Bradyarrhythmia } \\
\text { Normal } \\
\text { Unstable } \\
\text { Normal }\end{array}$ \\
\hline
\end{tabular}

of $53->400 \mathrm{pmol} / \mathrm{l}$ (reference range $<40$, remaining two patients 29 and $39 \mathrm{pmol} / \mathrm{l}$ ). This finding was not related to any abnormality of blood chemistry or foregut motor function.

In summary-as can be seen from the table, all patients with CRF had some foregut motility disorder, either in the form of GOR $(66.7 \%)$, abnormal gastric emptying $(58.3 \%)$, or antral dysrhythmia $(54.5 \%)$, and seven out of 12 $(58 \cdot 3 \%)$ had more than one abnormality, the most common association being between GOR and disordered gastric emptying.

\section{Discussion}

There is increasing evidence to suggest that anorexia, nausea, and vomiting result from a disturbance of foregut motility and its control mechanisms. ${ }^{7}$ This study clearly demonstrates that there are widespread motilty disorders affecting the foregut of children with CRF who present with these symptoms. The prevalence of GOR was high $(66.7 \%)$ and GOR was moderate to severe in $25 \%$. These findings confirm the observations of Ruley et al, who found GOR in 16/22 (73\%) infants with CRF and feeding problems. ${ }^{8}$

In this study, however, GOR was not the only cause of vomiting and abnormalities of gastric motor activity were as common. There have been no previous studies of gastric motor function in children with CRF, but studies in adults with CRF have yielded contradictory results. Some have shown delayed gastric emptying in symptomatic patients ${ }^{9}$ and during continuous ambulatory peritoneal dialysis, ${ }^{10}$ whereas normal gastric emptying has been reported in patients receiving haemodialysis, whether symptomatic or not. ${ }^{11} 12$ Our findings of both delayed and accelerated gastric emptying might be surprising, but both are in keeping with the patients' symptoms of fullness, nausea, and vomiting. ${ }^{13}$

During the pre-ejection phase of the vomiting reflex gastric antral dysrhythmias commonly occur in association with nausea and other autonomic symptoms. ${ }^{2}$ Gastric antral dysrhythmias have been described in different conditions in which the emetic reflex has been evoked ${ }^{14-18}$ and in both adults and children with severe unexplained vomiting. ${ }^{19-21}$ Although it might be expected that gastric electrical activity would affect gastric emptying, in only two patients was an antral dysrhythmia found as well as a disordered gastric emptying. The most likely explanation is that dysrhythmias result in impaired motor function of the gastric antrum which is mainly involved in grinding and emptying of solid foods. Emptying of a liquid meal depends mainly upon tonic pressure changes of the gastric fundus ${ }^{22}$ and thus antral dysrhythmias may not affect emptying of a liquid meal such as $5 \%$ glucose or milk. Furthermore, some of the dysrhythmias that we detected were more subtle and less striking than the continuous 'tachygastria' observed by others in patients with intractable vomiting. They may have been sufficient to induce nausea (and thereby a reduced food intake) but insufficient to affect gastric emptying. Secondly, some patients did not have the same meal volume (as they did not all tolerate the full meal) or the same test meal during the applied potential tomography and electrogastrography studies and a different challenge on the stomach might have resulted in different functional consequences. Finally, in nearly all patients gastric electrical control activity and gastric emptying were studied on two different occasions. Thus day to day variations might have been responsible for the lack of correlation between gastric emptying and gastric electrical control activity, perhaps due to fluctuations of some polypeptide hormones metabolised by the kidney and active on gut motility and food intake.

Gastrointestinal motility is modulated by myogenic, neural, and humoral factors, ${ }^{23}$ which may themselves be altered when the renal function is deranged. The variability of antral electrical control activity found in this study is in sharp contrast to the persistent dysrhythmias we have recently described in patients with disease of enteric nerves or smooth muscle. ${ }^{24}$ Thus it is likely that our present findings result from an altered humoral environment. In adults with CRF abnormally raised serum concentrations of several polypeptide hormones have been reported and hypergastrinaemia is a prominent biochemical feature. ${ }^{2526}$ In response to a meal, gastrin increases and stimulates gastric acid secretion and gastrointestinal motor activity by increasing antral contractions and disrupting the fasting motility pattern. ${ }^{27} \mathrm{At}$ pharmacological doses, like those seen in CRF, gastrin stimulates oesophageal, gall bladder and small bowel contractions, as well as gastric acid and pancreatic exocrine secretion. Acid hypersection and disruption of the fasting motility pattern with increased but incoordinate small bowel contractions all result in delayed gastric emptying. ${ }^{22}$ Therefore gastrin could be partly responsible for some of the motility disorders found in our study. However, other polypeptide hormones involved in the regulation of gut motility and the modulation of hunger and satiety are markedly increased in adults with $\mathrm{CRF}^{25}$ It is therefore very likely that in children with CRF hypergastrinaemia is only part of a more complex biochemical disorder that may be expected to have considerable effects on gut motility and food intake. In summary, this study demonstrates that children with CRF who suffer form anorexia, nausea, and vomiting have several motility disorders of the upper gastrointestinal tract. GOR is the 
cause of much vomiting, but reflex vomiting, with gastric dysrhythmias and disordered gastric emptying, is at least as common. We speculate that the altered humoral environment indicated by the hypergastrinaemia and generated by the CRF is at least in part responsible for the foregut motility disorders and the persistent anorexia.

AMR was supported in part by a grant (No 9002466.04) from the Consiglio Nazionale delle Ricerche, Rome, Italy.

1 Foreman JW, Chan JCM. Chronic renal failure in infants and children. F Pediatr 1988;113:793-800

2 Andrews PL, Hawthorn J. The neurophysiology of vomiting. Baillieres Clin Gastroenterol 1988;2:141-68.

3 Mahony MJ, Migliavacca M, Spitz L, Milla PJ. Motor disorders of the oesophagus in gastro-oesophageal reflux. Arch Dis Child 1988;63:1333-8

4 Devane SP, Panayotou J, Milla PJ. 6 hours post-prandial pH monitoring: an adequate test for gastro-oesophageal reflux monitoring: an adequate test for gastro-0esopha
in children and infants. Pediatr Res 1989;26:265.

5 Avill R, Mangnall YF, Bird NC, et al. Applied potential tomography. A new non invasive technique for measuring gastric emptying. Gastroenterology 1987;92:1019-26.

6 Stern RM, Koch KL, eds. Electrogastrography. Methodology, validation and applications. New York: Praeger, 1985

7 Stricker EM, Verbalis JG. Control of appetite and satiety: insights from biological and behavioural studies. Nutr Rev 1990;48:49-56.

8 Ruley EJ, Bock GH, Kerzner B, Abbott AW, Majd M, Chatoor I. Feeding disorders and gastroesophageal reflux in infants with chronic renal failure. Pediatr Nephrol 1989;3: 424-9.

9 McNamee PT, Moore GW, McGeown MG, Doherty CC. Gastric emptying in chronic renal failure. BMF 1985;291: 310-1.

10 Brown-Cartwright D, Smith HJ, Feldman M. Gastric emptying of an indigestible solid in patients with end-stage renal
disease on continuous ambulatory peritoneal dialysis. disease on continuous ambulat
Gastroenterology 1988;95:49-51.

11 Wright RA, Clemente R, Wathen R. Gastric emptying in patients with chronic renal failure receiving haemodialysis. Arch Intern Med 1984;144:495-6.

12 Freeman JG, Cobden I, Heaton A, Keir M. Gastric emptying in chronic renal failure. $B M 7$ 1985;291:1048.

13 Smout AJPM, Akkermans LMA. Postsurgical gastric emptying disorders. Motility. Clinical perspectives in gastroenterology. The Medicine Group (UK), 1990; No 11:15-9.

14 Sarna SK. Bowes KL, Daniel EE. Post-operative gastric electrical control activity in man. In: Daniel EE, ed. Gastroelectrical control activity in man. In: Daniel EE, ed. Gastro-
intestinal motility. Vancouver: Mitchell Press, 1974:73-83.

15 Abell TL, Camilleri M, Malagelada J-R. High prevalence of gastric electrical dysrhythmias in diabetic gastroparesis. gastric electrical dysrhythmia

16 Stern RM, Koch KL, Leibowitz HW, Lindblad IM, Schupert CL, Stewart WR. Tachigastria and motion sicknesss. Aviat Space Environ Med 1985;56:1074-7.

17 Koch KL, Creasy GW, Dwyer A, Vasey M, Stern RM Gastric dysrhythmia and nausea of pregnancy. Dig Dis $S c i$ 1987;32:909.

18 Abell TL, Malagelada J-R, Lucas AR, et al. Gastric electromechanical and neurohormonal function in anorexia nervosa. Gastroenterology 1987;93:958-65.

19 You CH, Lee KY, Chey WY, Menguy R. Electrogastrographic study of patients with unexplained nausea, bloating graphic study of patients with unexplained nause

20 Telander RL, Morgan KG, Kreulen DL, Schmalz PF, Kelly KA, Szurszewski JH. Human gastric atony with tachyKA, Szurszewski JH. Human gastric atony with tachygastria and

21 Cucchiara S, Janssens J, Vantrappen G, Geboes K, Ceccatelli P. Gastric electrical dysrhythmias (tachygastria and tachyarrhyhtmia) in a girl with chronic intractable vomiting. f Pediatr 1986;108:264-7.

22 Minami $\mathbf{H}$, McCallum RW. The physiology and pathophysiology of gastric emptying in humans. Gastroenterology 1984 86:1592-610.

23 Johnson LR, ed. Physiology of the gastrointestinal tract. New York: Raven Press, 1981.

24 Devane SP, Ravelli AM, Bisset WM, Smith VV, Lake BD Milla PJ. Gastric antral dysrhythmias in children with congenital idiopathic intestinal pseudo-obstruction. Gut 1992 (in press).

25 Owyang C, Miller LJ, DiMagno EP, Brennan LA, Go VLW. Gastrointestinal hormone profile in renal insufficiency. Mayo Clin Proc 1979;54:769-73.

26 Korman MG, Laver MC, Hansky J. Hypergastrinaemia in chronic renal failure. BMF 1972;i:209-10.

27 Mulholland MW, Debas HT. Physiology and pathophysiology of gastrin: a review. Surgery 1988;103:135-47. 